\title{
Bacillus Responses to Plant-Associated Fungal and Bacterial Communities
}

\author{
Sofija Andrić*t, Thibault Meyert and Marc Ongena* \\ Microbial Processes and Interactions Laboratory, Terra Teaching and Research Center, Gembloux Agro-Bio Tech, University \\ of Liège, Gembloux, Belgium
}

OPEN ACCESS

Edited by:

Soumitra Paul Chowdhury, Helmholtz Zentrum München,

Germany

Reviewed by:

Rainer Borriss,

Institut für Marine Biotechnologie e.V.

Germany

Anton Hartmann,

Helmholtz Zentrum München,

Germany

${ }^{*}$ Correspondence:

Sofija Andrić

sofija.andric@uliege.be

Marc Ongena

marc.ongena@uliege.be

${ }^{\dagger}$ These authors have contributed equally to this work

Specialty section:

This article was submitted to

Microbial Symbioses,

a section of the journal

Frontiers in Microbiology

Received: 09 April 2020

Accepted: 26 May 2020

Published: 23 June 2020

Citation:

Andrić S, Meyer T and Ongena M (2020) Bacillus Responses to Plant-Associated Fungal and Bacterial Communities.

Front. Microbiol. 11:1350. doi: 10.3389/fmicb.2020.01350
Some members of root-associated Bacillus species have been developed as biocontrol agents due to their contribution to plant protection by directly interfering with the growth of pathogens or by stimulating systemic resistance in their host. As rhizosphere-dwelling bacteria, these bacilli are surrounded and constantly interacting with other microbes via different types of communications. With this review, we provide an updated vision of the molecular and phenotypic responses of Bacillus upon sensing other rhizosphere microorganisms and/or their metabolites. We illustrate how Bacillus spp. may react by modulating the production of secondary metabolites, such as cyclic lipopeptides or polyketides. On the other hand, some developmental processes, such as biofilm formation, motility, and sporulation may also be modified upon interaction, reflecting the adaptation of Bacillus multicellular communities to microbial competitors for preserving their ecological persistence. This review also points out the limited data available and a global lack of knowledge indicating that more research is needed in order to, not only better understand the ecology of bacilli in their natural soil niche, but also to better assess and improve their promising biocontrol potential.

Keywords: Bacillus, rhizosphere, bioactive secondary metabolites, microbial interaction, biocontrol, molecular cross-talk, phenotype modulation

\section{INTRODUCTION}

Some Bacillus species of the B. subtilis complex are plant-associated and important members of the microbiome (Mendes et al., 2013; Müller et al., 2016; Fierer, 2017). During the last decades, their potential use as biocontrol agents with protective activity toward economically important plant pathogens has been highlighted thereby representing a promising alternative to chemical pesticides (Expósito et al., 2017; Fan et al., 2017; Finkel et al., 2017; Fira et al., 2018; Köhl et al., 2019). The efficacy of such bacilli in plant protection, as well as their constant presence in the strongly competitive rhizosphere niche, are due to their high potential to synthesize a wide range of volatile organic compounds (VOCs) and soluble bioactive secondary metabolites (BSMs). High structural diversity is observed in the patterns of VOCs formed by Bacillus (Caulier et al., 2019; Kai, 2020) but also in BSMs which can be either ribosomally synthesized and post-translationally modified like bacteriocins and lantibiotics or enzymatically formed via multi-modular mega-enzymes as in the case of polyketides (PKs), di-peptides or cyclic lipopeptides (CLPs) (Harwood et al., 2018; Kaspar et al., 2019; Rabbee et al., 2019). A prime role of some soluble BSMs and volatiles in plant protection is related to their strong antimicrobial activity leading to direct antagonism against plant 
pathogens (Raaijmakers and Mazzola, 2012; Borriss, 2015; Chowdhury et al., 2015a; Fan et al., 2018; Caulier et al., 2019; Rabbee et al., 2019; Kai, 2020). A second important biocontrolrelated trait of those compounds is their ability to trigger an immune reaction in the host plants which leads to systemic resistance (Induced SR) rendering the plant less susceptible to pathogen infection (Pieterse et al., 2014; Chowdhury et al., 2015a; Fan et al., 2018; Caulier et al., 2019; Rabbee et al., 2019). An additional role of BSMs is also linked to an efficient plant root colonization ability of Bacillus which indirectly protects the plant by decreasing the space and nutrient availability for pathogens (Raaijmakers et al., 2010; Borriss, 2015; Nayak et al., 2020). Some BSMs also contribute to colonization since they are involved in the developmental processes of Bacillus social motility and biofilm formation (Raaijmakers and Mazzola, 2012; Borriss, 2015; Pandin et al., 2017).

As rhizosphere-dwelling bacteria, these plant-associated bacilli are influenced by various environmental factors, such as temperature, $\mathrm{pH}$, moisture, light, and nutrient composition dictated by plant exudation (Santoyo et al., 2017). In this competitive niche, Bacillus species are also surrounded by and constantly interacting with a myriad of other (micro)organisms (Mendes et al., 2013; Traxler and Kolter, 2015; Fierer, 2017; Schmidt et al., 2019). In this review, we illustrate the diversity of BSMs produced by different Bacillus species and how this metabolome and phenotypic traits dictating ecological fitness can be impacted upon interaction with other fungal and bacterial microorganisms. The outcomes of volatile-based microbial interactions, in general, have been recently reviewed (Schmidt et al., 2015; Tyc et al., 2017). However, when dealing with interactions involving bacilli, information is scarce concerning possible changes in VOCs production upon cross-talk or perception of volatiles produced by other microorganisms (Chen et al., 2015; Tahir et al., 2017; Martínez-Cámara et al., 2019). Thus, we focus hereafter on interactions based on cross-talks mediated by the perception of soluble metabolites.

\section{DIVERSITY AND BIOACTIVITIES OF BACILLUS BSMS}

In the comparative genomic era, numerous adjustments have been done in the last years to clarify the phylogeny of the $B$. subtilis complex, which includes, among others, species, such as $B$. velezensis, B. amyloliquefaciens, B. atrophaeus, B. subtilis subspecies subtilis, $B$. licheniformis, $B$. pumilus, and B. siamensis with potential as biocontrol agents (Expósito et al., 2017; Fira et al., 2018; Maksimov et al., 2020), and which led to some confusion in species names but also to misassignments (Dunlap et al., 2016; Fan et al., 2017; Harwood et al., 2018; Du, 2019; Torres Manno et al., 2019). Many isolates, such as strains FZB42, QST713, or SQR9 formerly assigned to the $B$. subtilis or $B$. amyloliquefaciens species have been reclassified as $B$. velezensis representing the model species for plant-associated bacilli (Dunlap et al., 2016; Fan et al., 2017). A large part of the genome of these species is devoted to the production of antimicrobial compounds with up to $12 \%$ annotated as involved in the synthesis of bioactive secondary metabolites (Molinatto et al., 2016; Fan et al., 2017; Pandin et al., 2018).

Non-ribosomal metabolites are synthesized either by polyketide synthases (PKS) or non-ribosomal peptide synthase (NRPS), both acting as assembly lines catalyzing different steps for the incorporation of amino acid residues (Dutta et al., 2014; Winn et al., 2016; Bozhüyük et al., 2019). The three main families of Bacillus CLPs are surfactins, fengycins, and iturins (Figure 1). According to this limited number of families identified so far, the structural diversity of Bacillus CLPs may appear quite limited compared to other bacterial genera, such as Pseudomonas, for which many more different groups have been discovered (Geudens and Martins, 2018; Götze and Stallforth, 2020). However, reduced specificity of adenylation domains allows substitutions at specific places in the peptide chain and the NRPS machinery can bind different fatty acids with various chain lengths in the initiation step leading to co-production of various homologs within the three families as illustrated in Figure 1 (Kraas et al., 2010; Bozhüyük et al., 2019). Interestingly, some CLP peptidic variants are synthesized through species-specific clusters, like pumilacidin and lichenysin which are only produced respectively by $B$. pumilus and B. licheniformis (Figure 1).

The three different types of CLPs retain specific but complementary functions considering biocontrol efficiency and, more generally, ecological fitness of the producing strains. By contributing to motility and biofilm formation, surfactins are involved in colonization of plant tissues which indirectly allow Bacillus to outcompete phytopathogens for space and nutrients. Surfactins are also involved in the molecular cross-talk with the host and it is well-characterized as an elicitor of plant immunity leading to ISR (Ongena and Jacques, 2008; Henry et al., 2011; García-Gutiérrez et al., 2013; Cawoy et al., 2015; Chowdhury et al., 2015a). Direct antibiotic activity of surfactins at biologically relevant concentrations toward soil-dwelling or plant-associated microbes has been only occasionally reported (Qi et al., 2010; Liu et al., 2014). By contrast, fengycins and iturins are best characterized for their antifungal activities against a wide range of plant pathogens (Caulier et al., 2019; Rabbee et al., 2019). This is mainly due to their ability to perturb fungal cell membrane integrity resulting in cytoplasm leakage and finally hyphae death and inhibition of spore germination (Chitarra et al., 2003; Romero et al., 2007; Deleu et al., 2008; Etchegaray et al., 2008; Gong et al., 2015; Gao et al., 2017; Zhang and Sun, 2018). The three CLPs retain some selectivity but may also act synergistically to inhibit fungal growth (Liu et al., 2014). The lipid composition of the plasma membrane could explain differences in the sensitivity of fungal targets to one or more CLPs (Wise et al., 2014; Fiedler and Heerklotz, 2015).

Besides lipopeptides, most species of the B. subtilis group also produce other non-ribosomal oligopeptide derivatives, such as bacilysin, chlorotetaine, bacitracins, and rhizocticins which are known to be efficient as antibacterial compounds targeting cell wall biosynthesis (Zhao and Kuipers, 2016). The siderophore bacillibactin is highly conserved in the B. subtilis group (Figure 1) 


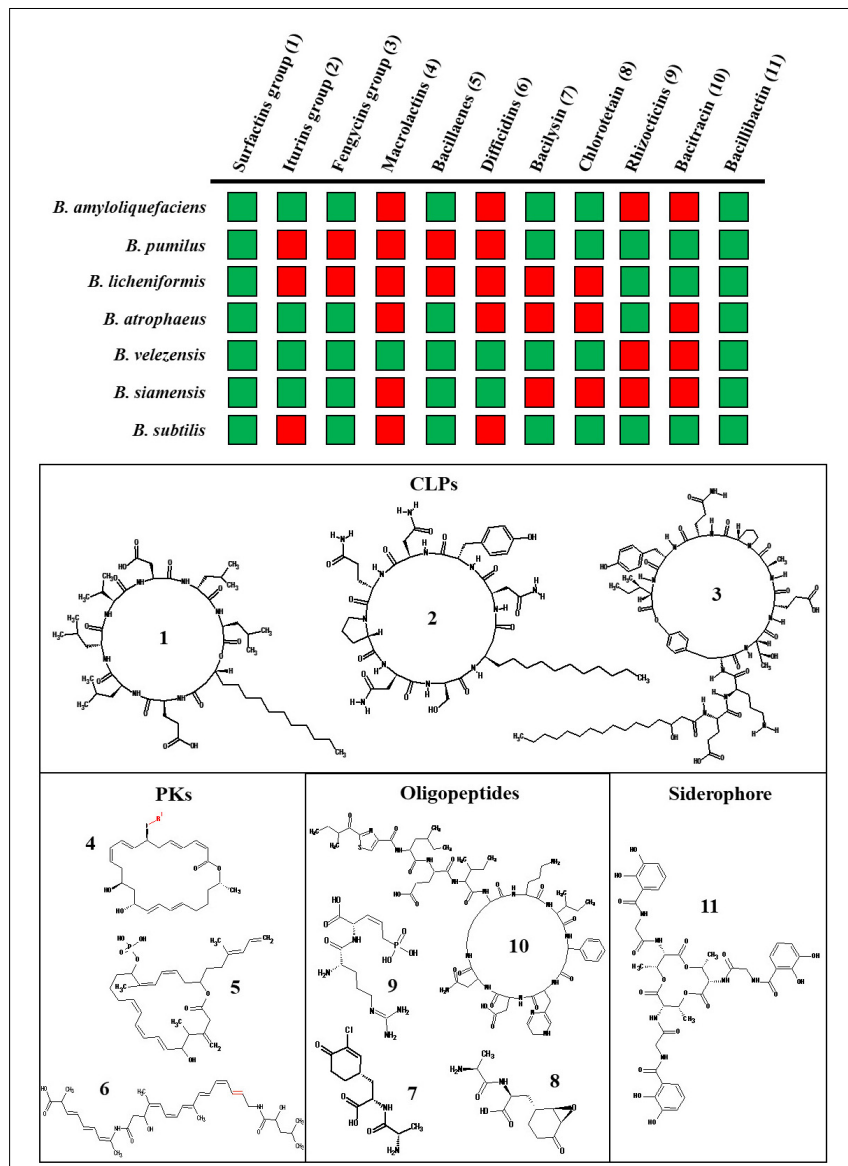

FIGURE 1 | Main non-ribosomal BSMs produced by the various species in the $B$. subtilis complex. The BSMs production is indicated for the following species $B$. subtilis, $B$. siamensis, B. velezensis, $B$. atrophaeus, $B$. amyloliquefaciens, $B$. pumilus, and $B$. licheniformis by a green square whereas red square indicates an absence of production of the BSMs in this species (Zhao and Kuipers, 2016; Fan et al., 2017; Harwood et al., 2018; Du, 2019; Torres Manno et al., 2019). The surfactins, iturins, and fengycins groups include lichenycin (1;AA1:L-GIn) and pumilacidin (1;AA4: L-Leu, AA7 = I-Ile); mycosubtilin (2;AA6: D-Ser, AA7 = L-Thr) and bacillomycin (2; AA6: D-Ser, AA7 = L-Asn); maltacin (4;AA1: L-Ser), agrastatin (4;AA10: L-Val) and plipastatin (4;AA9: D-Tyr), respectively. The structure of the representative metabolite is indicated by a number and represented below. The possible variations in the PKs structure are highlighted in red. For the macrolactin family, the main variants are $\mathrm{R}=\mathrm{H}$; $\mathrm{CO}-\mathrm{CH}_{2}-\mathrm{COOH}$; $\mathrm{CO}-\mathrm{CH}_{2}-\mathrm{CH}_{2}-\mathrm{COOH}$ or 6-O-succinyl- $\beta$-glucose (for review see Piel, 2010).

and is induced in response to iron limitation in the environment. It allows Bacillus to efficiently acquire $\mathrm{Fe}^{3+}$ and other metals (Miethke et al., 2006, 2008; Li et al., 2014) thereby depriving phytopathogens of this essential element (Miethke et al., 2006; Niehus et al., 2017).

Polyketide biosynthesis is performed by successive condensation of small carboxylic acids mediated by core domains of the corresponding enzyme machinery but some PKs are synthesized via hybrid NRPS/PKS systems leading to the integration of amino acid residues (Piel, 2010; Olishevska et al., 2019). The three main PKs produced by Bacillus are difficidins, macrolactins, and bacillaenes, the latter being more widespread across species (Figure 1). The main PKs role is related to their antibacterial activity via the ability to inhibit protein biosynthesis in numerous phytopathogenic bacteria but certain antifungal activity has been reported for bacillaenes and macrolactins (Caulier et al., 2019; Olishevska et al., 2019).

Ribosomally synthetized BSMs encompass bacteriocins and lantibiotics including plantazolicin, subtilin, ericin, mersacidin, amylolysin, and amylocyclicin that are specifically produced by some species or strains (Brötz et al., 1998; van Kuijk et al., 2012; Arguelles Arias et al., 2013; Scholz et al., 2014; Torres Manno et al., 2019). These BSMs are responsible for growth inhibition of Gram-positive bacteria by acting via different modes of action (Abriouel et al., 2011; Acedo et al., 2018).

\section{PERCEPTION OF FUNGI TRIGGERS THE PRODUCTION OF APPROPRIATE BSMS}

Several works have illustrated the impact of phytopathogenic fungi on BSMs production by soil bacilli. Some B. amyloliquefaciens, B. velezensis, and B. subtilis strains respond to the presence of antagonistic fungi by stimulating the production of the antifungal CLPs fengycins and/or iturins (Table 1). Not only the production of specific CLPs varies in a species-dependent manner but it is also highly dependent on the interacting fungal species. For example, much higher production of iturins and fengycins by B. subtilis $98 \mathrm{~S}$ was observed in confrontation with Pythium aphanidermatum and Fusarium oxysporum but not with Botrytis cinerea (Cawoy et al., 2015). Further, upon interaction with fungi, some B. velezensis strains (SQR9, FZB42, and S499) overproduced either iturins or fencycins ( $\mathrm{Li}$ et al., 2014; Chowdhury et al., 2015b; Kulimushi et al., 2017). For instance, Li et al. (2014) showed that when confronted with Sclerotinia sclerotiorum, $B$. velezensis SQR9 overproduces bacillomycin D (iturin family), but not fengycins. An overproduction of bacillomycin along with a reduced production of fengycins was also reported by Chowdhury et al. (2015b) upon B. velezensis FZB42 interaction with Rhizoctonia solani in the rhizosphere of lettuce plants. Differentially, Kulimushi et al. (2017), showed that strains S499 and FZB42 improved production of fengycin but not iturins upon interaction with Rhizomucor variabilis. Most of these studies also indicated that fengycins and iturins are the main BSMs responsible for antifungal activities (Table 1). Thus, Bacillus cells could specifically sense the presence of fungal competitors and accordingly overproduce appropriate antifungal BSMs to outcompete the interacting fungi. Moreover, besides modulating the production of fengycins and iturins, some strains of B. velezensis (SQR9, FZB42, and QST713) and B. subtilis (B9-5) may overproduce surfactins when sensing phytopathogenic fungi (Li et al., 2014; Chowdhury et al., 2015b; DeFilippi et al., 2018; Pandin et al., 2019). In support to this hypothesis, surfactin production of $B$. velezensis FZB42 was highly induced in the presence of fungal pathogen $R$. solani in the lettuce rhizosphere where it was found as the main produced compound (Chowdhury et al., 2015b). A similar response was recorded when $B$. velezensis SQR9 was confronted with 
S. sclerotiorum and Phytophthora parasitica (Li et al., 2014) or when B. subtilis B9-5 interacted in liquid medium with Rhizopus stolonifer (DeFilippi et al., 2018). In contrast to fengycins and iturins, surfactins are not strong direct antifungal metabolites in biologically relevant concentrations (Raaijmakers and Mazzola, 2012). Thus, it stays unclear why Bacillus responded by surfactin overproduction to the presence of antagonistic fungi. A possible explanation could be rooted in its global role promoting the rhizosphere and thereby, contributing to competition for nutrients and space with the interacting fungi (Ongena and Jacques, 2008; Rabbee et al., 2019).

Even though the siderophore bacillibactin is produced by all members of the B. subtilis species complex (Figure 1), its possible overproduction upon microbial interactions has been poorly investigated. Interestingly, the work of Li et al. (2014) showed that $B$. velezensis SQR9 overproduces bacillibactin when grown in presence of a range of fungi including $V$. dahliae, S. sclerotiorum, F. oxysporum, R. solani, F. solani, and P. parasitica. This may be interpreted as a response of the bacterium to some ironlimitation in the medium caused by the fungi via the release of their own chelatants.

In B. subtilis, the expression of many BSMs biosynthesis genes is transcriptionally fine-tuned by compound-specific regulation but also by global regulators governing the transition to crucial developmental processes like motility, biofilm formation and sporulation (Inaoka et al., 2009; López et al., 2009; VargasBautista et al., 2014). Fungal triggers may affect both types of regulatory systems involved in BSMs production. For instance, upon sensing $F$. verticillioides, the global stress-related regulator SigB is activated in B. subtilis NCIB3610 which in return enhances surfactin production (Bartolini et al., 2019). In interaction with F. culmorum under biofilm-conducive conditions, B. subtilis Bs 12 down-regulates the expression of the $\sin \mathrm{R}$ gene known as a repressor of biofilm formation which also negatively regulates surfactin production (Kearns et al., 2005; Khezri et al., 2016; Zhi et al., 2017). These observations strongly suggest that specific soluble signals, emitted by fungal pathogens, could be perceived by bacilli which in turn modulate BSMs synthesis. As observed by Bartolini et al. (2019), cells of the Bacillus colony, physically close to the fungal culture, responded to signals by over-expressing genes coding for transcription factors involved in CLPs synthesis regulation. In contrast, colony cells positioned on the opposite side of the fungi did not react to the fungus (Bartolini et al., 2019). This phenomenon indicates that the specific fungal metabolite diffuses on a short distance and has an influence on closely located Bacillus cells. Currently, no fungal compounds have been identified as triggers of BSM stimulation in Bacillus. Nonetheless, few commonly produced metabolites by Fusarium species were suggested to modify Bacillus behavior. It was shown that two cyclic depsipeptides (enniatins B1 and enniatins A1) and a pyrone (lateropyrone) had an antagonistic effect on B. subtilis growth (Ola et al., 2013). Fusaric acid also modified antibacterial activity of $B$. mojavensis but it was not related to a decrease in the production of specific BSMs (Bacon et al., 2004, 2006; Bani et al., 2014). These metabolites could also play a triggering role at sub-inhibitory concentration and could have an inducible effect on the range of Bacillus responses as has been shown for other signal metabolites (Bleich et al., 2015; Liu et al., 2018).

\section{BACILLUS PHENOTYPE IS MODULATED UPON PERCEPTION OF BACTERIAL COMPETITORS}

Some BSMs may also act as molecular determinants driving outcomes of interactions between B. subtilis and bacterial competitors as illustrated for the bacillaene polyketide displaying an essential protective role for survival in competition with Streptomyces soil isolates (Straight et al., 2007; Barger et al., 2012). However, there are few direct evidences for enhanced expression of BSMs upon interbacteria interactions. The only convincing examples involve the interaction of plant-associated bacilli with plant pathogens, such as Ralstonia solanacearum (Almoneafy et al., 2014) and Pseudomonas fuscovaginae (Kakar et al., 2014). In these two studies, improved expression of surfactin, bacilysin, and iturin biosynthesis genes were observed when Bacillus and pathogens were grown together in dual-cultures. Nevertheless, no clear indication about the enhanced production of the aforementioned BSMs based on their quantification nor improved antibacterial activities of Bacillus was presented as a result of this interaction.

Interestingly, at the phenotypical level, the development of soil bacilli is differentially altered upon sensing other bacteria from the same natural environment. Some of these phenotypical changes can be associated or due to a modulated production of specific BSMs. First, exogenous antibiotics or signals may stimulate biofilm formation which depends, to some extent, on surfactin production (López et al., 2009) and which may be viewed as a defensive response against exogenous toxic compounds and/or infiltration by competitors (Flemming et al., 2016; Townsley and Shank, 2017; Molina-Santiago et al., 2019). For instance, B. subtilis increased its relative subpopulation of biofilm matrix-producing cells in response to small molecules secreted by other bacterial species (López et al., 2009; Shank et al., 2011). The same phenomenon was illustrated for thiazolyl peptides emitted by closely related species, such as B. cereus and putatively formed by other soil microbes, such as Streptomyces isolates (Bleich et al., 2015). However, no change in surfactin production associated with the stimulation of biofilm was reported in these studies.

Besides biofilm formation, other mechanisms drive bacteria to initiate protective responses upon the detection of competitors. The flagellum-independent sliding motility is considered as an adaptive mechanism that allows bacterial cells to physically relocate in the context of a competitive interaction (Wadhams and Armitage, 2004; Jones et al., 2017; McCully et al., 2019). Upon sensing $S$. venezuelae, the $B$. subtilis ability to slide was increased (Liu et al., 2018). It depends in part on the production of surfactin (Grau et al., 2015; van Gestel et al., 2015) but a potential boost in lipopeptide synthesis upon the perception of the Streptomyces challenger was not demonstrated. Chloramphenicol and derivatives produced by $S$. venezuelae were identified as 
TABLE 1 | Change in expression and bioactivity of BSMs produced by members of $B$. subtilis group, upon interaction with fungal species.

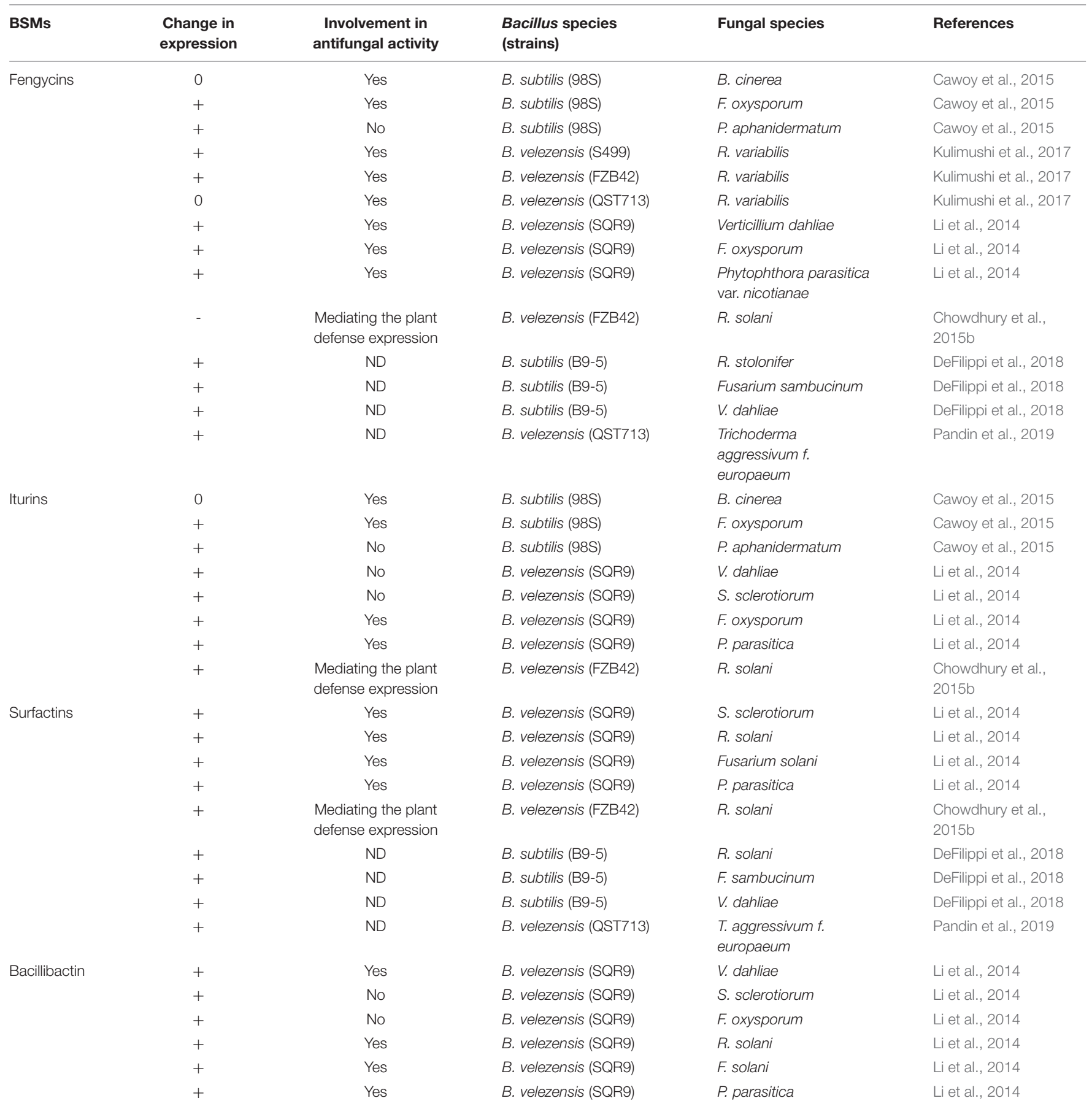

"O" indicates no changes, "+" enhanced and, "-"decreased BSMs production by Bacillus upon interaction with fungi. "Yes" indicates fungitoxic activity, "No" no antifungal activity, "ND" indicates that BSMs with antifungal activity are not detected.

molecular triggers acting at subinhibitory concentrations for inducing Bacillus motility (Liu et al., 2018).

Multiple bacteria promote sporulation in B. subtilis which represents another example of alteration of the physiological development of this species. In a context of distant interactions, exogenous siderophores accelerate the differentiation of Bacillus cells into spores. It was notably shown for enterobactin from
E. coli and for ferrioxamine E produced by Streptomycetes (Grandchamp et al., 2017). In iron-limited environments, B. subtilis cells would thus respond by taking up those "piratable" siderophores and start sporulating. This is not a general response to xenosiderophores since for instance, pyochelin from Pseudomonas does not affect Bacillus sporulation (MolinaSantiago et al., 2019). Nevertheless, the ability of siderophores 
to alter cellular differentiation in $B$. subtilis suggests that those molecules are likely to mediate complex microbial interactions in iron-depleted conditions, as often met in a soil environment. However, induction of $B$. subtilis sporulation by other bacteria may also occur in a cell-to-cell contact situation. Upon interaction with $P$. chlororaphis, its type VI secretion system acted as a trigger for sporulation, independently from its established role as cargo for delivering toxic effectors into the target Bacillus cells (García-Bayona and Comstock, 2018; Molina-Santiago et al., 2019).

That said, interspecies interactions may also result in inhibition rather than in stimulation of key developmental processes determining the fate of Bacillus multicellular communities. As an example, 2,4-diacetylphloroglucinol, a broad-spectrum antibiotic synthesized by fluorescent Pseudomonas, alters colony morphology, inhibits biofilm formation and sporulation in B. subtilis populations grown adjacent to $P$. protegens colonies (Powers et al., 2015). This antibiotic seems to act as an interspecific signaling molecule that inhibits bacterial differentiation at subinhibitory concentrations (Powers et al., 2015).

\section{CONCLUSION}

Here we provide an overview of the phenotypic and molecular responses of plant-beneficial soil bacilli upon sensing signals from other microorganisms that can be encountered in the rhizosphere niche. It is clear that BSMs production by Bacillus can be modulated upon interactions with other microbes and that key BSM-driven developmental processes may undergo unsuspected changes. It somehow illustrates the flexibility of these bacteria in re-directing their secondary metabolome to adapt environmental fitness upon sensing the presence of neighboring microorganisms. Nevertheless, the molecular mechanisms integrating the perception of exogenous triggers with a regulatory response leading to enhanced production of BSMs still remain unclear.

A significant boost in BSMs production by soil bacilli has been reported in most cases as an outcome from interactions with plant pathogenic fungi. This is of value in the context of biocontrol of fungal pathogens since direct antagonism is considered as the most powerful mode of action for suppression of plant diseases (Fravel, 2005; Frey-Klett et al., 2011; Köhl et al., 2019). By contrast, direct evidence for an impact of interbacteria interactions on the expression of the secondary metabolome in Bacillus is still globally missing. Nevertheless, interactionmediated variations in colony morphology, motility, biofilm

\section{REFERENCES}

Abriouel, H., Franz, C. M. A. P., Ben Omar, N., and Gálvez, A. (2011). Diversity and applications of Bacillus bacteriocins. FEMS Microbiol. Rev. 35, 201-232. doi: 10.1111/j.1574-6976.2010.00244.x

Acedo, J. Z., Chiorean, S., Vederas, J. C., and van Belkum, M. J. (2018). The expanding structural variety among bacteriocins from Gram-positive bacteria. FEMS Microbiol. Rev. 42, 805-828. doi: 10.1093/femsre/fu y033 formation, or sporulation illustrate how soil bacilli can protect themselves from antimicrobials emitted by bacterial competitors. Such an impact on those key developmental processes should thus be coupled with significant modulation in the production of specific BSMs underpinning these phenotypes. Depending on the concentration, these BSMs would then act as antimicrobials in interference competition or as signals in cooperative interspecies communication processes not necessarily affecting the growth of the partners (Bleich et al., 2015; Liu et al., 2018). However, this has yet to be thoroughly demonstrated and future examination of developmental controls for BSMs biosynthesis will likely bring light upon the key principles driving environmental fitness of soil bacilli as intrinsically influenced by interspecies competition.

From an ecological viewpoint, further investigations would also help to better understand why soil amendment with selected bacilli, even at high doses, do not durably impact the composition of the rhizosphere microbiome despite their huge arsenal in antimicrobial weapons (Correa et al., 2009; Chowdhury et al., 2013; Kröber et al., 2014; Qiao et al., 2017) and by contrast with some other bacteria and fungi (Buddrus-Schiemann et al., 2010; Chowdhury et al., 2013; Erlacher et al., 2014; Thomas and Sekhar, 2016; Wu et al., 2016). Those bacilli may thus provide protection to their host plant toward microbial pathogen ingress but would avoid detrimental effect on its naturally selected beneficial microbiome which is of prime interest for future application as biocontrol agents.

\section{AUTHOR CONTRIBUTIONS}

SA, TM, and MO conceived the idea, designed the outlines of the review, and wrote the manuscript. All authors listed have made a substantial, direct and intellectual contribution to the work, and approved it for publication.

\section{FUNDING}

Research in the laboratory was supported by the Interreg FWVL $\mathrm{V}$ portfolio project SmartBiocontrol, and by the Excellence of Science Grant 30650620 (F.R.S. - FNRS Fonds National de la Recherche Scientifique).

\section{ACKNOWLEDGMENTS}

We thank A. Argüelles-Arias, G. Hoff, and A. Rigolet for reading the manuscript and for their helpful suggestions.

Almoneafy, A. A., Kakar, K. U., Nawaz, Z., Li, B., Saand, M. A., Chun-lan, Y., et al. (2014). Tomato plant growth promotion and antibacterial related-mechanisms of four rhizobacterial Bacillus strains against Ralstonia solanacearum. Symbiosis 63, 59-70. doi: 10.1007/s13199-014-0288-9

Arguelles Arias, A., Ongena, M., Devreese, B., Terrak, M., Joris, B., and Fickers, P. (2013). Characterization of amylolysin, a novel lantibiotic from Bacillus amyloliquefaciens GA1. PLoS One 8:e83037. doi: 10.1371/journal.pone.0083037

Bacon, C. W., Hinton, D. M., and Hinton, A. (2006). Growth-inhibiting effects of concentrations of fusaric acid on the growth of Bacillus mojavensis and other 
biocontrol Bacillus species. J. Appl. Microbiol. 100, 185-194. doi: 10.1111/j. 1365-2672.2005.02770.x

Bacon, C. W., Hinton, D. M., Porter, J. K., Glenn, A. E., and Kuldau, G. (2004). Fusaric acid, a Fusarium verticillioides metabolite, antagonistic to the endophytic biocontrol bacterium Bacillus mojavensis. Can. J. Bot. 82, 878-885. doi: 10.1139/B04-067

Bani, M., Rispail, N., Evidente, A., Rubiales, D., and Cimmino, A. (2014). Identification of the main toxins isolated from Fusarium oxysporum f. sp. pisi race 2 and their relation with isolates' pathogenicity. J. Agric. Food Chem. 62, 2574-2580. doi: $10.1021 / \mathrm{jf} 405530 \mathrm{~g}$

Barger, S. R., Hoefler, B. C., Cubillos-Ruiz, A., Russell, W. K., Russell, D. H., and Straight, P. D. (2012). Imaging secondary metabolism of Streptomyces sp. $\mathrm{Mg} 1$ during cellular lysis and colony degradation of competing Bacillus subtilis. Antonie Van Leeuwenhoek 102, 435-445. doi: 10.1007/s10482-012-9769-0

Bartolini, M., Cogliati, S., Vileta, D., Bauman, C., Ramirez, W., and Grau, R. (2019). Stress responsive alternative sigma factor SigB plays a positive role in the antifungal proficiency of Bacillus subtilis. Appl. Environ. Microbiol. 85:e00178-19. doi: 10.1128/AEM.00178-19

Bleich, R., Watrous, J. D., Dorrestein, P. C., Bowers, A. A., and Shank, E. A. (2015). Thiopeptide antibiotics stimulate biofilm formation in Bacillus subtilis. Proc. Natl. Acad. Sci. U.S.A. 112, 3086-3091. doi: 10.1073/pnas. 1414272112

Borriss, R. (2015). "Bacillus, a plant-beneficial bacterium," in Principles of PlantMicrobe Interactions, ed. B. Lugtenberg, (Cham: Springer), 379-391. doi: 10. 1007/978-3-319-08575-3_40

Bozhüyük, K. A., Micklefield, J., and Wilkinson, B. (2019). Engineering enzymatic assembly lines to produce new antibiotics. Curr. Opin. Microbiol. 51, 88-96. doi: 10.1016/j.mib.2019.10.007

Brötz, H., Bierbaum, G., Leopold, K., Reynolds, P. E., and Sahl, H. G. (1998). The lantibiotic mersacidin inhibits peptidoglycan synthesis by targeting lipid II. Antimicrob. Agents Chemother. 42, 154-160. doi: 10.1128/AAC.42.1.154

Buddrus-Schiemann, K., Schmid, M., Schreiner, K., Welzl, G., and Hartmann, A. (2010). Root colonization by Pseudomonas sp. DSMZ 13134 and impact on the indigenous rhizosphere bacterial community of barley. Microb. Ecol. 60, 381-393. doi: 10.1007/s00248-010-9720-8

Caulier, S., Nannan, C., Gillis, A., Licciardi, F., Bragard, C., and Mahillon, J. (2019). Overview of the antimicrobial compounds produced by members of the Bacillus subtilis group. Front. Microbiol. 10:302. doi: 10.3389/fmicb.2019.00302

Cawoy, H., Debois, D., Franzil, L., De Pauw, E., Thonart, P., and Ongena, M. (2015). Lipopeptides as main ingredients for inhibition of fungal phytopathogens by Bacillus subtilis/amyloliquefaciens. Microb. Biotechnol. 8, 281-295. doi: 10.1111/1751-7915.12238

Chen, Y., Gozzi, K., Yan, F., and Chai, Y. (2015). Acetic acid acts as a volatile signal to stimulate bacterial biofilm formation. mBio 6:e0392-15. doi: 10.1128/mBio. 00392-15

Chitarra, G. S., Breeuwer, P., Nout, M. J. R., van Aelst, A. C., Rombouts, F. M., and Abee, T. (2003). An antifungal compound produced by Bacillus subtilis YM 10-20 inhibits germination of Penicillium roqueforti conidiospores. J. Appl. Microbiol. 94, 159-166. doi: 10.1046/j.1365-2672.2003.01819.x

Chowdhury, S. P., Dietel, K., Rändler, M., Schmid, M., Junge, H., Borriss, R., et al. (2013). Effects of Bacillus amyloliquefaciens FZB42 on lettuce growth and health under pathogen pressure and its impact on the rhizosphere bacterial community. PLoS One 8:e68818. doi: 10.1371/journal.pone.0068818

Chowdhury, S. P., Hartmann, A., Gao, X. W., and Borriss, R. (2015a). Biocontrol mechanism by root-associated Bacillus amyloliquefaciens FZB42 - a review. Front. Microbiol. 6:780. doi: 10.3389/fmicb.2015.00780

Chowdhury, S. P., Uhl, J., Grosch, R., Alquéres, S., Pittroff, S., Dietel, K., et al. (2015b). Cyclic lipopeptides of Bacillus amyloliquefaciens subsp. plantarum colonizing the lettuce rhizosphere enhance plant defense responses toward the bottom rot pathogen Rhizoctonia solani. Mol. Plant Microbe Interact. 28, 984-995. doi: 10.1094/mpmi-03-15-0066-r

Correa, O. S., Montecchia, M. S., Berti, M. F., Ferrari, M. C. F., Pucheu, N. L., Kerber, N. L., et al. (2009). Bacillus amyloliquefaciens BNM122, a potential microbial biocontrol agent applied on soybean seeds, causes a minor impact on rhizosphere and soil microbial communities. Appl. Soil Ecol. 41, 185-194. doi: 10.1016/j.apsoil.2008.10.007

DeFilippi, S., Groulx, E., Megalla, M., Mohamed, R., and Avis, T. J. (2018). Fungal competitors affect production of antimicrobial lipopeptides in Bacillus subtilis Strain B9-5. J. Chem. Ecol. 44, 374-383. doi: 10.1007/s10886-018-0938-0
Deleu, M., Paquot, M., and Nylander, T. (2008). Effect of fengycin, a lipopeptide produced by Bacillus subtilis, on model biomembranes. Biophys. J. 94, 26672679. doi: 10.1529/biophysj.107.114090

Du, Y., Ma, J., Yin, Z., Liu, K., Yao, G., Xu, W., et al. (2019). Comparative genomic analysis of Bacillus paralicheniformis MDJK30 with its closely related species reveals an evolutionary relationship between B. paralicheniformis and B. licheniformis. BMC Genomics. 20:283. doi: 10.1186/s12864-019-5646-9

Dunlap, C., Kim, S. J., Kwon, S. W., and Rooney, A. (2016). Bacillus velezensis is not a later heterotypic synonym of Bacillus amyloliquefaciens, Bacillus methylotrophicus, Bacillus amyloliquefaciens subsp. plantarum and 'Bacillus oryzicola' are later heterotypic synonyms of Bacillus velezensis based on phylogenomics. Int. J. Syst. Evol. Microbiol. 66, 1212-1217. doi: 10.1099/ijsem. 0.000858

Dutta, S., Whicher, J. R., Hansen, D. A., Hale, W. A., Chemler, J. A., Congdon, G. R., et al. (2014). Structure of a modular polyketide synthase. Nature 510, 512-517. doi: 10.1038/nature13423

Erlacher, A., Cardinale, C., Grosch, R., Grube, M., and Berg, G. (2014). The impact of the pathogen Rhizoctonia solani and its beneficial counterpart Bacillus amyloliquefaciens on the indigenous lettuce microbiome. Front. Microbiol. 5:175. doi: $10.3389 /$ fmicb.2014.00175

Etchegaray, A., de Castro Bueno, C., de Melo, I. S., Tsai, S. M., de Fátima Fiore, M., Silva-Stenico, M. E., et al. (2008). Effect of a highly concentrated lipopeptide extract of Bacillus subtilis on fungal and bacterial cells. Arch. Microbiol. 190, 611-622. doi: 10.1007/s00203-008-0409-z

Expósito, R. G., de Bruijn, I., Postma, J., and Raaijmakers, J. M. (2017). Current insights into the role of rhizosphere bacteria in disease suppressive soils. Front. Microbiol. 8:2529. doi: 10.3389/fmicb.2017.02529

Fan, B., Blom, J., Klenk, H. P., and Borriss, R. (2017). Bacillus amyloliquefaciens, Bacillus velezensis, and Bacillus siamensis form an "Operational Group B. amyloliquefaciens" within the B. subtilis species complex. Front. Microbiol. 8:22. doi: 10.3389/fmicb.2017.00022

Fan, B., Wang, C., Song, X., Ding, X., Wu, L., Wu, H., et al. (2018). Bacillus velezensis FZB42 in 2018: the gram-positive model strain for plant growth promotion and biocontrol. Front. Microbiol. 9:2491. doi: 10.3389/fmicb.2018. 02491

Fiedler, S., and Heerklotz, H. (2015). Vesicle leakage reflects the target selectivity of antimicrobial lipopeptides from Bacillus subtilis. Biophys. J. 109, 2079-2089. doi: $10.1016 /$ j.bpj.2015.09.021

Fierer, N. (2017). Embracing the unknown: disentangling the complexities of the soil microbiome. Nat. Rev. Microbiol. 15, 579-590. doi: 10.1038/nrmicro.20 17.87

Finkel, O. M., Castrillo, G., Herrera Paredes, S., Salas González, I., and Dangl, J. L. (2017). Understanding and exploiting plant beneficial microbes. Curr. Opin. Plant Biol. 38, 155-163. doi: 10.1016/j.pbi.2017.04.018

Fira, D., Dimkić, I., Berić, T., Lozo, J., and Stanković, S. (2018). Biological control of plant pathogens by Bacillus species. J. Biotechnol. 285, 44-55. doi: 10.1016/j. jbiotec.2018.07.044

Flemming, H. C., Wingender, J., Szewzyk, U., Steinberg, P., Rice, S. A., and Kjelleberg, S. (2016). Biofilms: an emergent form of bacterial life. Nat. Rev. Microbiol. 14, 563-575. doi: 10.1038/nrmicro.2016.94

Fravel, D. R. (2005). Commercialization and implementation of biocontrol. Annu. Rev. Phytopathol. 43, 337-359. doi: 10.1146/annurev.phyto.43.032904.092924

Frey-Klett, P., Burlinson, P., Deveau, A., Barret, M., Tarkka, M., and Sarniguet, A. (2011). Bacterial-Fungal interactions: hyphens between agricultural, clinical, environmental, and food microbiologists. Microbiol. Mol. Biol. Rev. 75, 583609. doi: $10.1128 / \mathrm{mmbr} .00020-11$

Gao, L., Han, J., Liu, H., Qu, X., Lu, Z., and Bie, X. (2017). Plipastatin and surfactin coproduction by Bacillus subtilis pB2-L and their effects on microorganisms. Antonie Van Leeuwenhoek 110, 1007-1018. doi: 10.1007/s10482-017-0874-y

García-Bayona, L., and Comstock, L. E. (2018). Bacterial antagonism in hostassociated microbial communities. Science 361:eaat2456. doi: 10.1126/science. aat 2456

García-Gutiérrez, L., Zeriouh, H., Romero, D., Cubero, J., de Vicente, A., and Pérez-García, A. (2013). The antagonistic strain Bacillus subtilis UMAF6639 also confers protection to melon plants against cucurbit powdery mildew by activation of jasmonate- and salicylic acid-dependent defence responses. Microb. Biotechnol. 6, 264-274. doi: 10.1111/1751-7915. 12028 
Geudens, N., and Martins, J. C. (2018). Cyclic lipodepsipeptides from Pseudomonas spp. - Biological swiss-army knives. Front. Microbiol. 9:1867. doi: 10.3389/ fmicb.2018.01867

Gong, A.-D., Li, H.-P., Yuan, Q.-S., Song, X.-S., Yao, W., He, W.-J., et al. (2015). Antagonistic mechanism of iturin A and plipastatin A from Bacillus amyloliquefaciens S76-3 from wheat spikes against Fusarium graminearum. PLoS One 10:e0116871. doi: 10.1371/journal.pone.0116871

Götze, S., and Stallforth, P. (2020). Structure, properties, and biological functions of nonribosomal lipopeptides from pseudomonads. Nat. Prod. Rep. 37, 29-54. doi: $10.1039 / C 9 N P 00022 \mathrm{D}$

Grandchamp, G. M., Caro, L., and Shank, E. A. (2017). Pirated siderophores promote sporulation in Bacillus subtilis. Appl. Environ. Microbiol. 83:e03293-16. doi: 10.1128/AEM.03293-16

Grau, R. R., De Oña, P., Kunert, M., Leñini, C., Gallegos-Monterrosa, R., Mhatre, E., et al. (2015). A duo of potassium-responsive histidine kinases govern the multicellular destiny of Bacillus subtilis. mBio 6:e00581-15. doi: 10.1128/mBio. 00581-15

Harwood, C. R., Mouillon, J.-M., Pohl, S., and Arnau, J. (2018). Secondary metabolite production and the safety of industrially important members of the Bacillus subtilis group. FEMS Microbiol. Rev. 42, 721-738. doi: 10.1093/femsre/ fuy028

Henry, G., Deleu, M., Jourdan, E., Thonart, P., and Ongena, M. (2011). The bacterial lipopeptide surfactin targets the lipid fraction of the plant plasma membrane to trigger immune-related defence responses. Cell. Microbiol. 13, 1824-1837. doi: $10.1111 /$ j.1462-5822.2011.01664.x

Inaoka, T., Wang, G., and Ochi, K. (2009). ScoC regulates bacilysin production at the transcription level in Bacillus subtilis. J. Bacteriol. 191, 7367-7371. doi: 10.1128/JB.01081-09

Jones, S. E., Ho, L., Rees, C. A., Hill, J. E., Nodwell, J. R., and Elliot, M. A. (2017). Streptomyces exploration is triggered by fungal interactions and volatile signals. eLife 6:e21738. doi: 10.7554/eLife.21738

Kai, M. (2020). Diversity and distribution of volatile secondary metabolites throughout Bacillus subtilis isolates. Front. Microbiol. 11:559. doi: 10.3389/ fmicb.2020.00559

Kakar, K. U., Duan, Y. P., Nawaz, Z., Sun, G., Almoneafy, A. A., Hassan, M. A., et al. (2014). A novel rhizobacterium Bk7 for biological control of brown sheath rot of rice caused by Pseudomonas fuscovaginae and its mode of action. Eur. J. Plant Pathol. 138, 819-834. doi: 10.1007/s10658-013-0356-7

Kaspar, F., Neubauer, P., and Gimpel, M. (2019). Bioactive secondary metabolites from Bacillus subtilis: a comprehensive review. J. Nat. Prod. 82, 2038-2053. doi: 10.1021 /acs.jnatprod.9b00110

Kearns, D. B., Chu, F., Branda, S. S., Kolter, R., and Losick, R. (2005). A master regulator for biofilm formation by Bacillus subtilis. Mol. Microbiol. 55, 739-749. doi: 10.1111/j.1365-2958.2004.04440.x

Khezri, M., Jouzani, G. S., and Ahmadzadeh, M. (2016). Fusarium culmorum affects expression of biofilm formation key genes in Bacillus subtilis. Braz. J. Microbiol. 47, 47-54. doi: 10.1016/j.bjm.2015.11.019

Köhl, J., Kolnaar, R., and Ravensberg, W. J. (2019). Mode of action of microbial biological control agents against plant diseases: relevance beyond efficacy. Front. Plant Sci. 10:1-19. doi: 10.3389/fpls.2019.00845

Kraas, F. I., Helmetag, V., Wittmann, M., Strieker, M., and Marahiel, M. A. (2010). Functional dissection of surfactin synthetase initiation module reveals insights into the mechanism of lipoinitiation. Chem. Biol. 17, 872-880. doi: 10.1016/j. chembiol.2010.06.015

Kröber, M., Wibberg, D., Grosch, R., Eikmeyer, F., Verwaaijen, B., Chowdhury, S. P., et al. (2014). Effect of the strain Bacillus amyloliquefaciens FZB42 on the microbial community in the rhizosphere of lettuce under field conditions analyzed by whole metagenome sequencing. Front. Microbiol. 5:252. doi: 10 . 3389/fmicb.2014.00252

Kulimushi, P. Z., Arias, A. A., Franzil, L., Steels, S., and Ongena, M. (2017). Stimulation of fengycin-type antifungal lipopeptides in Bacillus amyloliquefaciens in the presence of the maize fungal pathogen Rhizomucor variabilis. Front. Microbiol. 8:850. doi: 10.3389/fmicb.2017. 00850

Li, B., Li, Q., Xu, Z., Zhang, N., Shen, Q., and Zhang, R. (2014). Responses of beneficial Bacillus amyloliquefaciens SQR9 to different soilborne fungal pathogens through the alteration of antifungal compounds production. Front. Microbiol. 5:636. doi: 10.3389/fmicb.2014.00636
Liu, Y., Kyle, S., and Straight, P. D. (2018). Antibiotic stimulation of a Bacillus subtilis migratory response. mSphere 3:e00586-17. doi: 10.1128/mSphere. 00586-17

Liu, Y., Zhang, N., Qiu, M., Feng, H., Vivanco, J. M., Shen, Q., et al. (2014). Enhanced rhizosphere colonization of beneficial Bacillus amyloliquefaciens SQR9 by pathogen infection. FEMS Microbiol. Lett. 353, 49-56. doi: 10.1111/ 1574-6968.12406

López, D., Vlamakis, H., Losick, R., and Kolter, R. (2009). Cannibalism enhances biofilm development in Bacillus subtilis. Mol. Microbiol. 74, 609-618. doi: 10. 1111/j.1365-2958.2009.06882.x

Maksimov, I. V., Singh, B. P., Cherepanova, E. A., Burkhanova, G. F., and Khairullin, R. M. (2020). Prospects and applications of lipopeptide-producing bacteria for plant protection (Review). Appl. Biochem. Microbiol. 56, 15-28. doi: $10.1134 / \mathrm{S} 0003683820010135$

Martínez-Cámara, R., Montejano-Ramírez, V., Moreno-Hagelsieb, G., Gustavo, S., and Valencia-Cantero, E. (2019). The volatile organic compound dimethylhexadecylamine affects bacterial growth and swarming motility of bacteria. Folia Microbiol. 65, 523-532. doi: 10.1007/s12223-019-00756-6

McCully, L. M., Bitzer, A. S., Seaton, S. C., Smith, L. M., and Silby, M. W. (2019). Interspecies Social Spreading: interaction between two sessile soil bacteria leads to emergence of surface motility. mSphere 4:e00696-18. doi: 10.1128/msphere. 00696-18

Mendes, R., Garbeva, P., and Raaijmakers, J. M. (2013). The rhizosphere microbiome: significance of plant beneficial, plant pathogenic, and human pathogenic microorganisms. FEMS Microbiol. Rev. 37, 634-663. doi: 10.1111/ 1574-6976.12028

Miethke, M., Klotz, O., Linne, U., May, J. J., Beckering, C. L., and Marahiel, M. A. (2006). Ferri-bacillibactin uptake and hydrolysis in Bacillus subtilis. Mol. Microbiol. 61, 1413-1427. doi: 10.1111/j.1365-2958.2006.05321.x

Miethke, M., Schmidt, S., and Marahiel, M. A. (2008). The major facilitator superfamily-type transporter YmfE and the multidrug-efflux activator Mta mediate bacillibactin secretion in Bacillus subtilis. J. Bacteriol. 190, 5143-5152. doi: 10.1128/JB.00464-08

Molina-Santiago, C., Pearson, J. R., Navarro, Y., Berlanga-Clavero, M. V. Caraballo-Rodriguez, A. M., Petras, D., et al. (2019). The extracellular matrix protects Bacillus subtilis colonies from Pseudomonas invasion and modulates plant co-colonization. Nat. Commun. 10:1919. doi: 10.1038/s41467-019-09 944-x

Molinatto, G., Puopolo, G., Sonego, P., Moretto, M., Engelen, K., Viti, C., et al. (2016). Complete genome sequence of Bacillus amyloliquefaciens subsp. plantarum S499, a rhizobacterium that triggers plant defences and inhibits fungal phytopathogens. J. Biotechnol. 238, 56-59. doi: 10.1016/j.jbiotec.2016.09. 013

Müller, D. B., Vogel, C., Bai, Y., and Vorholt, J. A. (2016). The plant microbiota: systems-level insights and perspectives. Annu. Rev. Genet. 50, 211-234. doi: 10.1146/annurev-genet-120215-034952

Nayak, S. K., Nayak, S., and Patra, J. K. (2020). "Rhizobacteria and its biofilm for sustainable agriculture: a concise review" in New and Future Developments in Microbial Biotechnology and Bioengineering, eds J. S. Singh, and D. P. Singh, (Amsterdam: Elsevier), 165-175. doi: 10.1016/B978-0-444-64279-0.0 0013-X

Niehus, R., Picot, A., Oliveira, N. M., Mitri, S., and Foster, K. R. (2017). The evolution of siderophore production as a competitive trait. Evolution 71, 14431455. doi: 10.1111/evo.13230

Ola, A. R. B., Thomy, D., Lai, D., Brötz-Oesterhelt, H., and Proksch, P. (2013). Inducing secondary metabolite production by the endophytic fungus Fusarium tricinctum through coculture with Bacillus subtilis. J. Nat. Prod. 76, 2094-2099. doi: $10.1021 / \mathrm{np} 400589 \mathrm{~h}$

Olishevska, S., Nickzad, A., and Déziel, E. (2019). Bacillus and Paenibacillus secreted polyketides and peptides involved in controlling human and plant pathogens. Appl. Microbiol. Biotechnol. 103, 1189-1215. doi: 10.1007/s00253018-9541-0

Ongena, M., and Jacques, P. (2008). Bacillus lipopeptides: versatile weapons for plant disease biocontrol. Trends Microbiol. 16, 115-125. doi: 10.1016/j.tim.2007. 12.009

Pandin, C., Darsonval, M., Mayeur, C., Le Coq, D., Aymerich, S., and Briandet, R. (2019). Biofilm formation and synthesis of antimicrobial compounds by the biocontrol agent Bacillus velezensis QST713 in an Agaricus bisporus compost 
micromodel. Appl. Environ. Microbiol. 85:e00327-19. doi: 10.1128/AEM.0032719

Pandin, C., Le Coq, D., Canette, A., Aymerich, S., and Briandet, R. (2017). Should the biofilm mode of life be taken into consideration for microbial biocontrol agents? Microb. Biotechnol. 10, 719-734. doi: 10.1111/1751-7915.12693

Pandin, C., Le Coq, D., Deschamps, J., Védie, R., Rousseau, T., Aymerich, S., Briandet, R. (2018). Complete genome sequence of Bacillus velezensis QST713: a biocontrol agent that protects Agaricus bisporus crops against the green mould disease. J. Biotechnol. 278, 10-19. doi: 10.1016/j.jbiotec.2018.04.014

Piel, J. (2010). Biosynthesis of polyketides by trans-AT polyketide synthases. Nat. Prod. Rep. 27, 996-1047. doi: 10.1039/b816430b

Pieterse, C. M. J., Zamioudis, C., Berendsen, R. L., Weller, D. M., Van Wees, S. C. M., and Bakker, P. A. H. M. (2014). Induced systemic resistance by beneficial microbes. Annu. Rev. Phytopathol. 52, 347-375.

Powers, M. J., Sanabria-Valentín, E., Bowers, A. A., and Shank, E. A. (2015). Inhibition of cell differentiation in Bacillus subtilis by Pseudomonas protegens. J. Bacteriol. 197, 2129-2138. doi: 10.1128/JB.02535-14

Qi, G., Zhu, F., Du, P., Yang, X., Qiu, D., Yu, Z., et al. (2010). Lipopeptide induces apoptosis in fungal cells by a mitochondria-dependent pathway. Peptides 31, 1978-1986. doi: 10.1016/J.PEPTIDES.2010.08.003

Qiao, J. Q., Yu, X., Liang, X. J., Liu, Y. F., Borriss, R., and Liu, Y. Z. (2017). Addition of plant-growth-promoting Bacillus subtilis PTS-394 on tomato rhizosphere has no durable impact on composition of root microbiome. BMC Microbiol. 17:131. doi: 10.1186/s12866-017-1039-x

Raaijmakers, J. M., de Bruijn, I., Nybroe, O., and Ongena, M. (2010). Natural functions of lipopeptides from Bacillus and Pseudomonas: more than surfactants and antibiotics. FEMS Microbiol. Rev. 34, 1037-1062. doi: 10.1111/ j.1574-6976.2010.00221.x

Raaijmakers, J. M., and Mazzola, M. (2012). Diversity and natural functions of antibiotics produced by beneficial and plant pathogenic bacteria. Annu. Rev. Phytopathol. 50, 403-424. doi: 10.1146/annurev-phyto-081211-172908

Rabbee, M., Ali, M., Choi, J., Hwang, B., Jeong, S., Baek, K., et al. (2019). Bacillus velezensis: a valuable member of bioactive molecules within plant microbiomes. Molecules 24:1046. doi: 10.3390/molecules24061046

Romero, D., de Vicente, A., Rakotoaly, R. H., Dufour, S. E., Veening, J.-W., Arrebola, E., et al. (2007). The Iturin and Fengycin families of lipopeptides are key factors in antagonism of Bacillus subtilis toward Podosphaera fusca. Mol. Plant Microbe Interact. 20, 430-440. doi: 10.1094/MPMI-20-4-0430

Santoyo, G., Hernández-Pacheco, C., Hernández-Salmerón, J., and HernándezLeón, R. (2017). The role of abiotic factors modulating the plant-microbe-soil interactions: toward sustainable agriculture. A review. Span. J. Agric. Res. 15, $1-15$.

Schmidt, R., Cordovez, V., De Boer, W., Raaijmakers, J., and Garbeva, P. (2015). Volatile affairs in microbial interactions. ISME J. 9, 2329-2335. doi: 10.1038/ ismej.2015.42

Schmidt, R., Ulanova, D., Wick, L., Bode, H., and Garbeva, P. (2019). Microbedriven chemical ecology: past, present and future. ISME J. 13, 2656-2663. doi: 10.1038/s41396-019-0469-x

Scholz, R., Vater, J., Budiharjo, A., Wang, Z., He, Y., Dietel, K., et al. (2014). Amylocyclicin, a novel circular bacteriocin produced by Bacillus amyloliquefaciens FZB42. J. Bacteriol. 196, 1842-1852. doi: 10.1128/JB.0147414

Shank, E. A., Klepac-Ceraj, V., Collado-Torres, L., Powers, G. E., Losick, R., and Kolter, R. (2011). Interspecies interactions that result in Bacillus subtilis forming biofilms are mediated mainly by members of its own genus. Proc. Natl. Acad. Sci. U.S.A. 108, E1236- E1243. doi: 10.1073/pnas.11036 30108

Straight, P. D., Fischbach, M. A., Walsh, C. T., Rudner, D. Z., and Kolter, R. (2007). A singular enzymatic megacomplex from Bacillus subtilis. Proc. Natl. Acad. Sci. U.S.A. 104, 305-310. doi: 10.1073/pnas.0609073103

Tahir, H. A. S., Gu, Q., Wu, H., Raza, W., Safdar, A., Huang, Z., et al. (2017). Effect of volatile compounds produced by Ralstonia solanacearum on plant growth promoting and systemic resistance inducing potential of Bacillus volatiles. BMC Plant. Biol. 17:133. doi: 10.1186/s12870-017-1083-6

Thomas, P., and Sekhar, A. C. (2016). Effects due to rhizospheric soil application of an antagonistic bacterial endophyte on native bacterial community and its survival in soil: a case study with Pseudomonas aeruginosa from banana. Front. Microbiol. 7:493. doi: 10.3389/fmicb.2016.00493

Torres Manno, M. A., Pizarro, M. D., Prunello, M., Magni, C., Daurelio, L. D., and Espariz, M. (2019). GeM-Pro: a tool for genome functional mining and microbial profiling. Appl. Microbiol. Biotechnol. 103, 3123-3134. doi: 10.1007/ s00253-019-09648-8

Townsley, L., and Shank, E. A. (2017). Natural-product antibiotics: cues for modulating bacterial biofilm formation. Trends Microbiol. 25, 1016-1026. doi: 10.1016/j.tim.2017.06.003

Traxler, M. F., and Kolter, R. (2015). Natural products in soil microbe interactions and evolution. Nat. Prod. Rep. 32, 956-970. doi: 10.1039/c5np00013k

Tyc, O., Song, C., Dickschat, J. S., Vos, M., and Garbeva, P. (2017). The ecological role of volatile and soluble secondary metabolites produced by soil bacteria. Trends Microbiol. 25, 280-292. doi: 10.1016/j.tim.2016.12.002

van Gestel, J., Vlamakis, H., and Kolter, R. (2015). From cell differentiation to cell collectives: Bacillus subtilis uses division of labor to migrate. PLoS Biol. 13:e1002141. doi: 10.1371/journal.pbio.1002141

van Kuijk, S., Noll, K. S., and Chikindas, M. L. (2012). The species-specific mode of action of the antimicrobial peptide subtilosin against Listeria monocytogenes Scott A. Lett. Appl. Microbiol. 54, 52-58. doi: 10.1111/j.1472-765X.2011.03 170.x

Vargas-Bautista, C., Rahlwes, K., and Straight, P. (2014). Bacterial competition reveals differential regulation of the pks genes by Bacillus subtilis. J. Bacteriol. 196, 717-728. doi: 10.1128/JB.01022-13

Wadhams, G. H., and Armitage, J. P. (2004). Making sense of it all: bacterial chemotaxis. Nat. Rev. Mol. Cell Biol. 5, 1024-1037. doi: 10.1038/nrm1524

Winn, M., Fyans, J. K., Zhuo, Y., and Micklefield, J. (2016). Recent advances in engineering nonribosomal peptide assembly lines. Nat. Prod. Rep. 33, 317-347. doi: $10.1039 / \mathrm{c} 5 \mathrm{np} 00099 \mathrm{~h}$

Wise, C., Falardeau, J., Hagberg, I., and Avis, T. J. (2014). Cellular lipid composition affects sensitivity of plant pathogens to Fengycin, an antifungal compound produced by Bacillus subtilis strain CU12. Phytopathology 104, 1036-1041. doi: 10.1094/PHYTO-12-13-0336-R

Wu, B., Wang, X., Yang, L., Yang, H., Zeng, H., Qiu, Y. M., et al. (2016). Effects of Bacillus amyloliquefaciens ZM9 on bacterial wilt and rhizosphere microbial communities of tobacco. Appl. Soil Ecol. 103, 1-12. doi: 10.1016/j.apsoil.2016. 03.002

Zhang, L., and Sun, C. (2018). Fengycins, cyclic lipopeptides from marine Bacillus subtilis Strains, kill the plant-pathogenic fungus Magnaporthe grisea by inducing reactive oxygen species production and chromatin condensation. Appl. Environ. Microbiol. 84:e00445-18. doi: 10.1128/AEM.00445-18

Zhao, X., and Kuipers, O. P. (2016). Identification and classification of known and putative antimicrobial compounds produced by a wide variety of Bacillales species. BMC Genomics 17:882. doi: 10.1186/s12864-016-3224-y

Zhi, Y., Wu, Q., and Xu, Y. (2017). Genome and transcriptome analysis of surfactin biosynthesis in Bacillus amyloliquefaciens MT45. Sci. Rep. 7:40976. doi: 10.1038/ srep40976

Conflict of Interest: The authors declare that the research was conducted in the absence of any commercial or financial relationships that could be construed as a potential conflict of interest.

Copyright (C) 2020 Andrić, Meyer and Ongena. This is an open-access article distributed under the terms of the Creative Commons Attribution License (CC BY). The use, distribution or reproduction in other forums is permitted, provided the original author(s) and the copyright owner(s) are credited and that the original publication in this journal is cited, in accordance with accepted academic practice. No use, distribution or reproduction is permitted which does not comply with these terms. 